forms. Hum Mol Genet, 1996, 5: 95 102

10 陈雨亭, Sittler A, 余 珢, 等. 用酵母双杂交体系篮选与 FMRP 相互作用蛋白的 cDNA. 中国医学科学院学报, 1998, 20 (3) : 173 178

11 Ausubel F M, Brent R, Kingston R E, et al. Short Protocols in Molecular Biology, 3 rd ed. New York: John Wiley \& Son Inc, 1992. $131 \sim 13-61$

12 Sambrook J, Fritsch E F, Maniatis T, et al. Molecular Cloning, 2nd ed. New York: Cold Spring Harbor Laboratory Press, 1987

13 Fields S, Sternglanz R. The two hybrid system: an assay for proteirr protein interactions. TIBS, 1994, 10: 286 292

14 Fromont-Racine M, Rain J C, Legrain P. Toward a functional analysis of the yeast genome through exhaustive two hybrid screens. Nature Genetics, 1997, 16: 277 282

15 Bartel P L, Roecklein J A, SenGupta D, et al. A protein linkage map of Escherichia coli bacteriophage T7. Nature Genetics, 1996, 12: $72 \sim 77$

16 Neddermann P. Gallinari P. Lettieri T. et al. Cloning and expression of human G/T mismatchr specific thvmine DNA glvcosvlase. J Biol Chem, 1996, 271: 12767 12774

$17 \mathrm{Um} \mathrm{S}$, Harbers H, Beneck A, et al. Retinoic acid receptors interact physically and functionally with the T: G mismatch specific thymine DNA glycosylase. J Biol Chem, 1998, 273: 20728 20736

18 Bardoni B, Sittler A, Shen Y, et al. Analysis of domains affecting intracellular localization of the FMRP protein. Neurobiology of Disease, 1997, 4: 329 336

\title{
树轮宽度对近 376 年呼和浩特季节降水的重建
}

\author{
刘禹 马利民 \\ (中国科学院黄土与第四纪地质国家重点实验室, 西安 710054)
}

摘要 基于树轮宽度指标, 精确重建了呼和浩特过去近 376 年以来 2 6 月降水总量的演变历 史, 解释方差为 $56 \%$ 。 历史文献记载的旱灾年份在重建序列上均有所反映。两者无论在年际 间高频还是在 10 年尺度的低频变化均具有很好的一致性. 周期分析表明: 呼和浩特 2 6 月 降水含有 $40,5.33,5.10,4.55$ 和 $2.09,2.03$ 年的显著周期.

\section{关键词＼cjkstart呼和浩特 大青山 树轮宽度年表 降水重建}

树木年轮( 见封面) 以其分辨率高( 年或季节)、记录连续性好和重建精度较高等优势, 成为 全球变化研究中获取过去气候环境演变数据的重要方法之一. 位于东亚夏季风最北缘、地处 干旱_半干旱地区的阴山横亘于内蒙古中部地区, 东西狭长, 是通过内蒙古的一道重要地理分 界线. 大青山主峰海拔 $2300 \mathrm{~m}$. 这里气候干燥, 降水量少, 且年际变率大. 山脉南侧年平均 气温 $6 \sim 8{ }^{\circ} \mathrm{C}$, 年降水量一般为 $400 \mathrm{~mm}$. 干旱是这一地区发生频率最高、危害最严重的自然灾 害 ${ }^{1]}$. 本文将就如何从树木年轮中提取季节降水变化的信息进行讨论.

\section{1 样品采集}

在阴山地区, 由于受自然和人为因素的双重影响, 现存森林已极其稀少, 可供选择的采样 点非常有限. 根据我们的研究目标和样本的可采情况, 将采样位置定在大青山南坡的喇嘛洞 
$\left(40^{\circ} 48^{\prime} \mathrm{N}, 111^{\circ} 17^{\prime} 30^{\prime \prime} \mathrm{E}\right.$, 海拔 $\left.1300 \mathrm{~m}\right)$. 距呼和浩特市以西约 $20 \mathrm{~km}$.

该地优势树种为油松( Pinus tabulaeformis), 夹杂有少量杜松( Juniperus rigida)、侧柏( Platycladus orientalis)、白桦(Betula platyphylla) 等. 采样点附近大范围土壤贫脊, 植被稀蔬, 树木之间 郁闭度低 $(<0.01)$. 树木均长于岩石风化物之上, 降水是该地树木生长的主要限制因子, 这 是比较典型的树轮取样环境. 用于研究的树种为油松, 基于国际树木年轮库( ITRDB) 的标准, 采集了 15 棵现生树, 每树以生长雉从不同方向取 2 芯. 所有样本均取自山脊线上. 采集时间 为 1997 年 7 月.

样本经干燥、固定和打磨(用 320 mesh 砂纸) 后, 应用树轮研究的基本方法 SKELETON PLOT $\backslash+[2]$ 进行交叉定年, 确保每一生长年轮具有准确的日历年龄. 之后, 在精度为 0.01 mm 的Velmax_1测宽仪上逐芯逐轮测定年轮宽度. 根据量测结果, 采用 COFECHA ${ }^{[3]}$ 计算机程序 进行交叉定年的质量控制. 结果表明, 呼和浩特组全部样本总共缺轮数 62 轮, 占全部轮数的 $1.049 \%$. 统计特征中各序列与主序列相关系数 $(r)$ 范围为 $0.354 \sim 0.770$, 均值 0.56 ; 平均敏感 度 $(\mathrm{ms})$ 为 $0.221 \sim 0.501$, 均值 0.352 ; 自相关系为 $0.356 \sim 0.909$, 均值 0.75 . 反映出该组树木群 体受气候因素控制较为强烈, 各样本宽度序列中明显保留着树木前期生长的滞后效应, 当年的 树木生长会影响树木未来的生长.

\section{2 年表的建立}

树轮宽度年表的建立通过 $\operatorname{ARSTAN}^{[4]}$ 程序完成, 这一过程中消除了: (1) 树木生长中与年 龄增长相关联的生长趋势; (2) 部分树木之间的非一致性扰动, 排除其中非气候信号. 所建立 的年表长度为 $533 \mathrm{a}$, 考虑到样芯复本, 可靠长度为 $376 \mathrm{a}$. 通过试用不同步长的样条函数, 对 该地区而言, 如果取 $55 \mathrm{a}$ 步长对各个宽度序列进行拟合, 则可以保有最多的气候变化的高频 信号. 而选用步长为 $250 \mathrm{a}$ 的样条函数进行拟合, 将会保留更多的低频信号 (将在另文讨论). 本文的讨论全部基于 $55 \mathrm{a}$ 步长样条函数拟合的结果.

图 1 为最终建立的标准年表(STD)、差值年表(RES) 和自回归标准化年表(ARS). 表 1 为 3 个年表的若干基本统计量. 表 2 为标准化序列与差值序列的统计量, 其中 A 为所有序列间的 平均相关系数; B 为树与树之间的平均相关系数; C 为同株树 2 个芯之间的平均相关系数; PC1 表示第 1 主分量解释总方差的百分比. 表 1 中 RES 年表类型 1 阶自相关系数与标准差较 STD 小, 平均敏感度较大, 定量说明了 RES 年表保留的高频振荡信息比 STD 为多, 而这种振荡正是 树木对当年气候环境变化的响应.

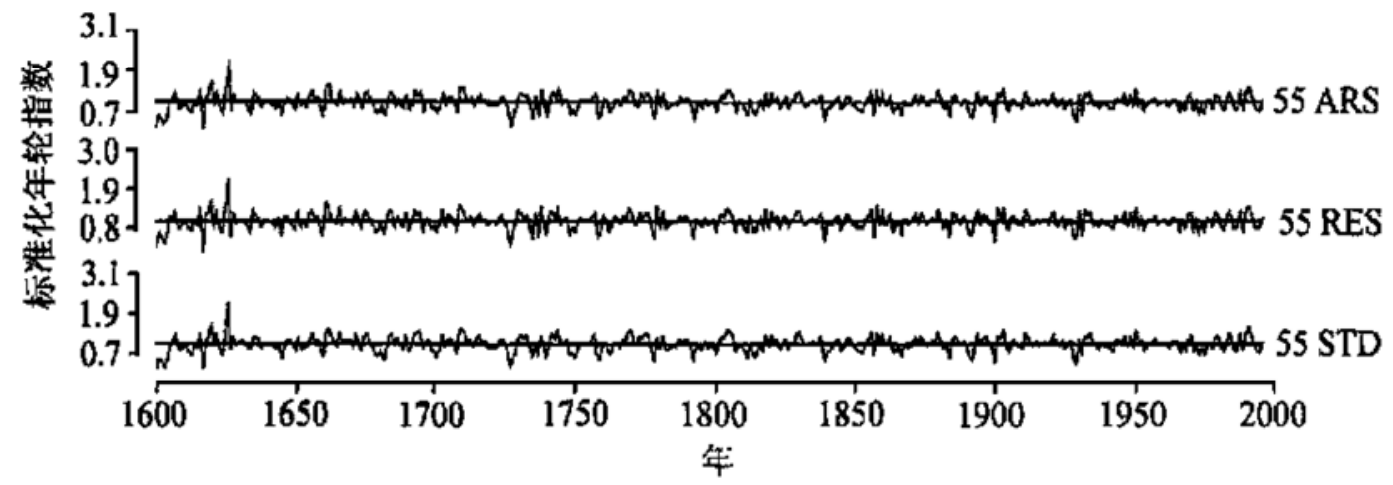

图 1 内蒙古大青山 STD, RES 和 ARS 年表 
表 1 STD, RES 和 ARS 年表的统计量

\begin{tabular}{cccccccc}
\hline 年表类型 & 平均值 & 中位数 & 平均敏感度 & 标准差 & 1 阶自相关系数 & 偏度 & 峰度 \\
\hline STD & 1.00 & 0.99 & 0.34 & 0.37 & 0.20 & 1.53 & 8.21 \\
RES & 1.00 & 0.98 & 0.37 & 0.36 & -0.01 & 1.38 & 7.06 \\
ARS & 1.00 & 0.98 & 0.35 & 0.37 & 0.12 & 1.61 & 8.50 \\
\hline
\end{tabular}

表 2 标准化序列与差值序列的统计量

\begin{tabular}{ccccc}
\hline 序列 & A & B & C & PC1 \\
\hline 去趋势序列 & 0.45 & 0.44 & 0.46 & 50.87 \\
差值序列 & 0.48 & 0.47 & 0.49 & 53.40 \\
\hline
\end{tabular}

\section{3 气候响应分析}

用于分析的气象站为采样点东北 $20 \mathrm{~km}$ (直线距离) 的呼和浩特市气象站 $\left(40^{\circ} 49^{\prime} \mathrm{N}\right.$, $111^{\circ} 41^{\prime} \mathrm{E}$, 海拔 $1063 \mathrm{~m}$ ), 观测资料为 $1951 \sim 1996$ 年, 计 45 a. 气象资料使用前, 采用 Mann_ Kendall $^{[5]}$ 和双重量分析法 (Double_mass analy sis) ${ }^{[6]}$ 对该站记录进行了检验, 参考站选用包头 市和固阳县站. 结果表明, 呼和浩特市温度、降 水记录无随机突变和不均匀分布情况, 代表了自 然界的实际变化.

年轮宽度对气候的响应, 主要通过响应函数 和相关函数计算而获得. 响应函数由 PRE$\mathrm{CON}^{[7]}$ 完成. 分析时段为 1952 1996 年, 气候因

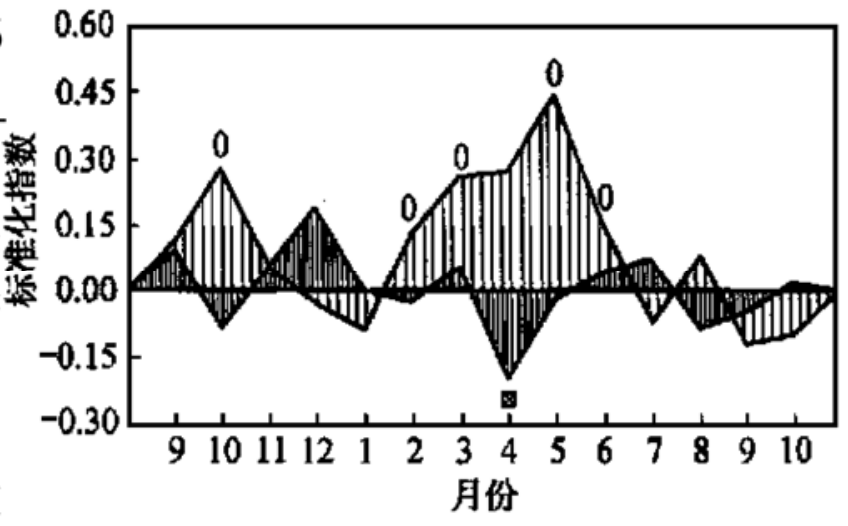

图 $2 \mathrm{RES}$ 年表的响应函数图

111 降水, III)气温( 0 , 凶表示超过 $95 \%$ 置信水平) 子选用树木生长前期(即上 1 年 9 月) 至当年 10 月的各月平均气温和降水量, 共计 28 个因子. STD, RES 和 ARS 年表对气温基本均不表现出 显著响应, 但对降水呈显著响应, 且月份均集中在上 1 年 10 月和当年 $2 \sim 6$ 月 (正响应)。3 种 年表相比较, RES 年表所含气候变动的方差贡献高达 $75.5 \%$ 。就其响应的月份而言, 具有明确 的植物生理学意义. 图 2 为 RES 的响应函数图. 表 3 为 3 种年表分别与各月降水的相关系 数.

进一步计算获得的 STD, RES 及 ARS 对 2 6 月降水的相关系数分别为 $0.656,0.669$ 和 0.662 , 其中以 RES 最高. 这表明 RES 年表更适宜用于大青山 2 6 月份降水量重建.

表 3 呼和浩特年表与降水相关函数分析结果 ${ }^{\mathrm{a})}$

\begin{tabular}{|c|c|c|c|c|c|c|c|c|c|c|c|c|c|c|}
\hline 月份 & 1 & 2 & 3 & 4 & 5 & 6 & 7 & 8 & 9 & 10 & 11 & 12 & $2 \sim 6$ & $4 \sim 6$ \\
\hline STD & -0 & 0.313 & 0.310 & $0.353^{*}$ & 0.390 & 0.271 & 0.106 & 0.184 & $-0.351^{*}$ & -0.216 & -0.206 & -0.104 & $0.656^{*}$ & $0.607^{\prime \prime}$ \\
\hline RES & -0.144 & 0.307 & 0.252 & $0.379^{*}$ & $0.372^{*}$ & 0.308 & 0.087 & 0.225 & -0.324 & -0.160 & -0.247 & -0.126 & $0.669^{*}$ & $0.642^{*}$ \\
\hline ARS & -0.124 & 0.311 & 0.285 & $0.377^{*}$ & $0.379^{*}$ & 0.282 & 0.121 & 0.213 & $-0.347^{\circ}$ & -0.213 & -0.206 & -0.132 & $0.662^{*}$ & $0.622^{\prime \prime}$ \\
\hline
\end{tabular}

a) 表内* 表示该值超过了 $99 \%$ 的置信水平

4 气候重建

图 3 为经过标准化后的 RES 年表与 2 6 月降水距平的比较. 因为气象资料较短, 便采用 逐一剔除法 (leave_one_out) ${ }^{[8]}$ 检验. 结果相关系数 $r$ 值变幅稳定可靠, 同时表明 1965 年较为异 
常, 这一年内蒙古地区出现较大范围的春夏连 旱, 为多年少见 ${ }^{[9,10]}$. 可见 RES 年表对春夏连 旱反映并不敏感. 移去 1965 年后, 经计算, 相 关系数提高到 0.712 , 校准方差达到 $50.70 \%$. 在用树轮资料进行古气候重建时, 常考虑采用 多元逐步回归技术, 使得重建更为精确一些. 经典的树轮气候学认为 $t$ 年的年轮在形成时, 它不仅受到当年气候的占统治地位的影响, 还 受到上 2 年 $(t-1, t-2)$ 的滞后效应 ${ }^{[1]}$.

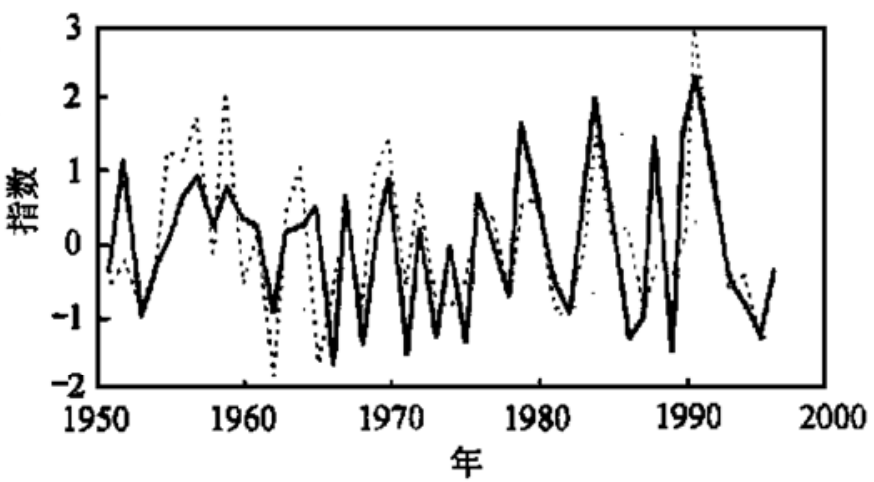

图 $3 \mathrm{RES}$ (实线) 与 2 6 月降水距平 (虚线) 的比较

基于这点, 我们在 RES 年表( 此处称为 $\operatorname{RES}_{(t)}$ ) 的基础上, 制做了另两个年表, $\operatorname{RES}_{(t-1)}$ (前 1 年) 和 $\operatorname{RES}_{(t-2)}$ (前 2 年). $\operatorname{RES}_{(t)}$ 与 $\operatorname{RES}_{(t-1)}, \operatorname{RES}_{(t-2)}$ 的相关系数分别为 -0.04 和- 0.08 , 三者不存在显著相关, 这种情况正是较为理想的使用多元回归的先决条件 ${ }^{[4]}$. 最终的转换函 数因此设计为

$$
R_{26}=1325.14 \operatorname{RES}_{(t)}+274.01 \mathrm{RES}_{(t-1)}-151.23 \operatorname{RES}_{(t-2)}-371.47 \text {, }
$$

这一函数式的复相关系数为 0.75 , 方差解释量为 $56 \%$, 调整后为 $53 \%, F$ 检验值为 $16.73, P$ 小 于 0.00001 . 就其方差解释量而言, 较简单回归有显著提高.

图 4 为重建的 1620 1996 年( 376 年) 时段内呼和浩特地区春季至夏初( 2 6 月) 的降水变 化时间序列.

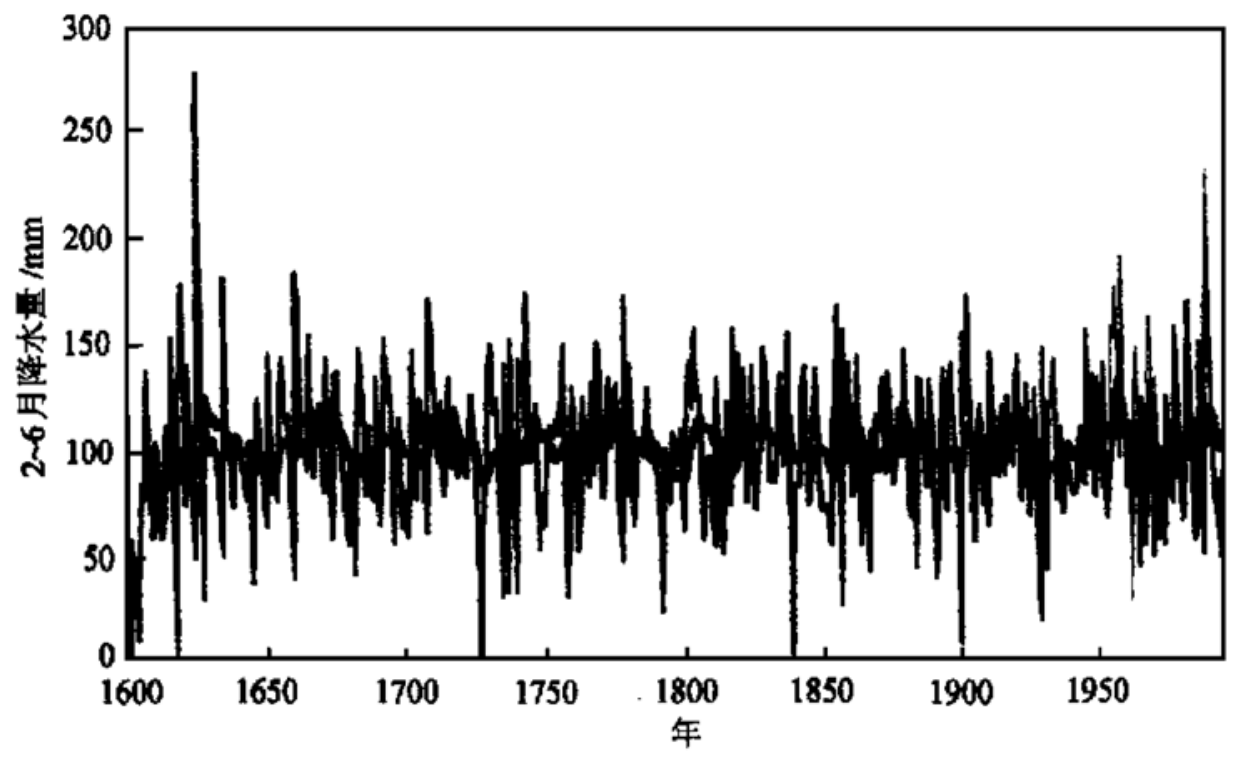

图 4 呼和浩特地区 1620 1996 年春季至夏初(2 6 月) 的降水重建

图 4 中粗线为 13 年滑动平均值, 目的在于强调 10 年尺度的变化. 图 4 所展示的数据表 明树轮重建值在高频与低频变化方面与现代观测值(图中右部细线)有相当好的一致性和精确 性. 但两者之间仍有差别. 重建的 2 6 月降水总量的极大值与极小值并不能在振幅上完全 与观测值重合, 这反映出我们所采用的回归方程比较谨慎合理. 重建曲线有如下特点:

(1) 春至初夏旱灾频繁. 呼和浩特地区 1620 年以来( 376 年间), 2 6 月降水在 $50 \mathrm{~mm}$ 左 右的有 36 年(约占全部年份的 $9 \%$ ), 降水> $150 \mathrm{~mm}$ 的年有 34 年,约占 $9 \%$.

(2) 值得指出的是重建图反映的历史上几次特大(春至初夏) 连旱的年份有: 1628, 1727 
$1728,1740,1792,1839 \sim 1840,1867,1877,1891 \sim 1892,1900$ 和 1928 1929 等 9 年(段). 1929 年 之后呼和浩特地区特大旱情况再未超出上述年份.

(3) 呼和浩特地区 2 6 月自 1975 年以后年际间降水变率明显增大, 与历史上 1726 1744 年时段颇为相象.

(4) 功率谱分析表明, 呼和浩特地区 2 6 月降水含有 40, 5. 33, 5. 10, 4. 55 和 2.09, 2. 03 年 的显著周期.

呼和浩特地区的重建时段主要是春、夏初, 而这一时间的干旱对农牧业生产有最直接、最 严重的危害. 干旱可使牧草返青推迟, 从而影响产量. 严重干旱时造成饥荒, 而形成灾年. 历 史上对此多有记载.

\section{5 树轮重建值精确性的检验}

$56 \%$ 解释方差量表明树轮数据可以在很大程度上有效地解释大青山地区 2 6 月降水的 实际值. 除了上述的实测值与重建值对比以及逐一剔除法以外, 我们还采用下述方法来检验 树轮气候重建值的可靠性与精确性:

(1) 符号检验 $(\text { sign test })^{[12,13]}$ : 结果表明, 在 45 年观测中, 2 6 月降水变化的高频(A) 和低 频 (B) 变化均达到了 0.01 置信水平所要求的年数 (表 4).

表 4 2 6 月降水的符号检验结果 ${ }^{a}$

\begin{tabular}{cccc}
\hline & $n$ & $n_{\mathrm{a}}(1) 95 \%$ & $n_{\mathrm{b}}(2) 99 \%$ \\
\hline $\mathrm{A}$ & 35 & 30 & 32 \\
$\mathrm{~B}$ & 37 & 31 & 33 \\
\hline
\end{tabular}

a) 数据长度原始值 $n=44,1$ 阶 $n^{\prime}=43$

(2) 误差缩减 $(\mathrm{RE})^{[12]}$ : 此为普遍应用的精确检验气候重建值可靠性的统计量. 取值在 $[-\infty, 1]$, 其值越大证明重建越可靠. 此研究中的 RE 为 0.39 , 取值较理想.

(3) 乘积平均数 (product mean, $t$ ) 检验 ${ }^{[12]}$ : 用以检验重建序列和实测序列间同号年与异 号年之间在量值上是否存在显著差异. 此研究中 $t=2.83$, 表明 $2 \sim 6$ 月降水重建序列与实测 序列十分接近.

(4) 历史记录: 除了以上数理统计检验外, 历史记录也可以从另一个方面佐证本文重建 的可靠性. 图 5 为重建值与旱涝记载的对比. 旱涝指数引自文献 [14].

可以看出, 两条曲线无论是年际间的高频振荡还是 $10 \mathrm{a}$ 尺度间的低频变化, 均有相当好 的一致性. 历史记载 ${ }^{1)}{ }^{2)}$ 的旱涝年份在重建序列中均有所反映. 如较严重的旱年记载有:

1877 年, 呼和浩特、包头等. 特大干旱, 一年无雨.

1878 年, 土默川右旗, 呼和浩特、包头大旱灾.

1892 年, 呼和浩特、包头、土默川右旗大旱灾, 入春至夏无雨, 不能下种, 秋收无望. 全境 赤地千里.

1900 年, 土默川左旗、包头特大旱, 春夏秋旱, 颗粒不收, $\cdots$

1928 年, 呼和浩特, 旱.

1929 年, 内蒙古大部, 旱荒至, 延长 4 年之久, 本年春夏滴雨未落, 禾皆枯死, 寸草不生.

1) 内蒙古自治区历代灾害史. 内蒙古自治区参事室编, 1976

2) 内蒙古及临近地区气象灾害旱漟丰欠年表. 内蒙古自治区气象科学研究所编, 1975 


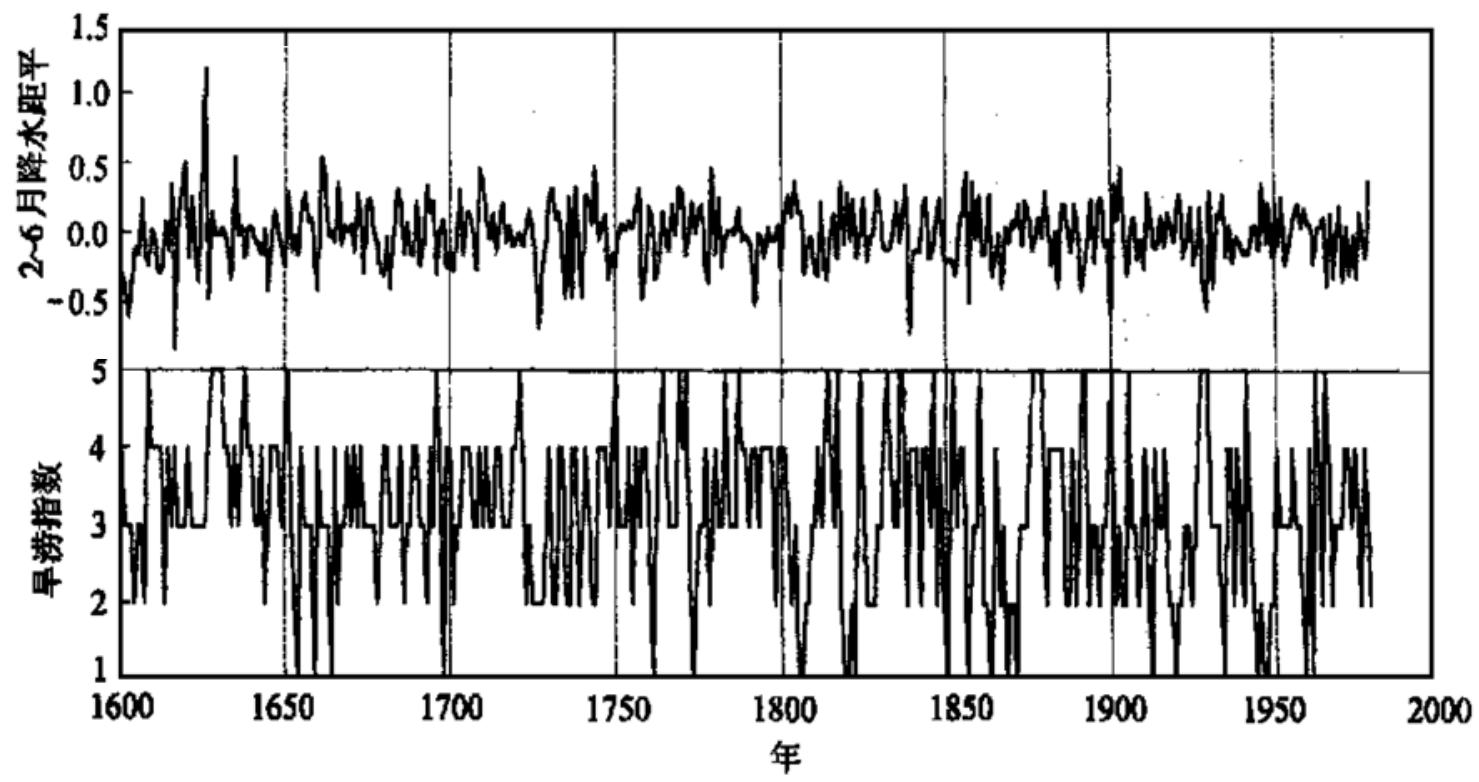

图 5 2 6月降水重建距平与旱港指数的对比 旱涝等级划分: 1 一涝, 2 - 偏涝, 3 - 正常, 4 —偏早, 5 一早

以上这些检验从不同方面证明了本文所用树轮资料重建的可靠性.

至于这一地区干旱成因, 目前是一个很复杂的问题. 从宏观上讲, 这一地区属温带大陆性 气候, 海拔在 $1000 \mathrm{~m}$ 以上, 远离海洋, 冬季常受寒冷的气团控制; 夏季副热带高压北抬, 南来 水汽逐渐增多, 雨水相对较多, 但又常因冷空气活动偏北, 冷暖空气在这一地区交汇的机会不 多, 多数时间受副热带和大陆高压影响, 干旱少雨. 有时受蒙古冷涡控制, 多雷阵雨, 雨量不 均; 有时受西来天气系统影响, 又因影响部位不同, 产生较大范围降雨的机会也不甚多 ${ }^{101}$. 由 于受地理位置和大气环流的基本背景的影响, 造成了上述地区降水量偏少, 易于出现干旱的情 况.

致谢 研究中曾同安芷生院士、吴国雄教授、王绍武教授进行了有益的讨论, 郡雪梅教授提供功率谱计算程 序, 作者在此一并表示衷心感谢。本工作为国家自然科学基金“九五”重大基金( 批准号: 49894170)、中国科学 院“九五”重点项目( 批准号: KZ_952_S1_419)、中国科学院“九五”重大项目( 批准号: KZ951_A1_402) 资助.

\section{参 考 文 献}

1 王文辉. 内蒙古气候. 北京: 气象出版社, 1990. 1 273

2 Stokes M A, Smiley T L. An introduction to tree_ring dating. Chicago: University of Chicago Press, 1968. 1 73

3 Holmes R L. Computer_assisted quality control in tree_ring dating and measurement. Tree_ring Bulletin, 1983, 43: 69 75

4 Cook E R, Kairiukstis L A. Methods of dendrochronology. The Netherlands, Dordrecht: Kluwer Academic Publishers, 1990. 1 200

5 Mann H B. Non_parametric test against trend. Econometrika, 1945, 13: 245 259

6 Kohler M A. On the use of double_mass analysis for testing the consistency of meteorological records and for making required adjustments. Bull Amer Meteorol Soc, 1949, 30: 188 189

7 Fritts H C, Shashkin A V. Modeling tree_ring structure as related temperature, precipitation, and day length. In: Lewis T E, ed. Dendrochronology and dendrochemistry in forest health monitoring. CRC Press, Cleveland, USA, 1991. 1 39

8 Mosteller F, Tukey J W. Data analysis and regression. Reading, Massachusetts: Addison_Wesley Publishing Company, 1977. 1 588

9 王长根. 内蒙古气候热点及对策研究. 北京: 气象出版社, 1997. 1 168

10 吴鸿宾. 内蒙古自治区主要气象灾害分析( 1947 1987). 北京: 气象出版社, 1990. 1 219 
11 Fritts H C. Tree ring and climate. London: Academy Press, 1976. 1 567

12 Fritts H C. Reconstructing large_scale climatic patterns from tree_ring data. Tucson, Arizona: The University of Arizona Press, 1991. $1 \sim 286$

13 刘 禹, 邵雪梅, 吴祥定, 等. 树轮密度、稳定 C 同位素对过去 100 年陕西黄陵的季节气温与降水的恢复. 中国科学, D 辑, 1997, (27) 3: 271 277

14 中央气象局气象科学研究院主编. 中国近五百年旱涝分布图集. 北京: 地图出版社, 1981. 1 332

\title{
桂东南钾玄质侵入岩带及其岩石学和 地球化学特征
}

\author{
李献华 (4) 周汉文 (니) 刘颖李寄嵎 (피) \\ 孙敏 (4) 陈正宏 ${ }^{(\text {(U丩) }}$
}

( 中国科学院广州地球化学研究所, 广州 510640; 4香港大学地球科学系, 香港薄扶林道;

(四)台湾大学地质学系, 台北 106 17)

摘要 野外地质、岩石学、元素地球化学研究表明, 广西东南部中生代二长岩、正长岩以及与之 共生的碱性花岗岩岩体属钾玄质系列岩石, 从而厘定出一北东向展布的钾玄质侵入岩带。这 些钾玄质侵入岩富集大离子亲石元素、高场强元素和稀土元素, 而且无明显的 $\mathrm{Nb}, \mathrm{Ta}$ 亏损, 与 板内型或裂谷型钾玄岩相似, 表明其形成与岛弧无关, 而很可能是在中生代区域软流圈地幔上 涌和岩石圈伸展构造背景下形成的.

\section{关键词 钾玄质岩石 岩石学 元素地球化学 广西}

钾玄质岩石 ( shoshonitic rock) 是一类高碱 $\left(\mathrm{K}_{2} \mathrm{O}+\mathrm{Na}_{2} \mathrm{O}>5 \%\right.$ )、高 $\mathrm{K}_{2} \mathrm{O} / \mathrm{Na}_{2} \mathrm{O}$ 比(当 $\mathrm{SiO}_{2}=$ $50 \%$ 和 $55 \%$ 时, $\mathrm{K}_{2} \mathrm{O} / \mathrm{Na}_{2} \mathrm{O}>0.5$ 和 1.0 )、低 $\mathrm{TiO}_{2}$ (大多数 $<1.3 \%$ )、 $\mathrm{Al}_{2} \mathrm{O}_{3}$ 含量高且变化范围大 (大多数介于 $14 \% \sim 19 \%$ )、强烈富集大离子亲石元素和轻稀土元素的富碱高钾岩浆岩 ${ }^{11}$, 包 括火山岩 (橄辉安粗岩、钾玄岩、粗面粒玄岩等) 和侵入岩 (主要为钾质二长岩和正长岩)。对新 生代钾玄质岩石的研究表明, 钾玄质岩石主要起源于与俯冲作用有关的富钾和大离子亲石元 素交代地幔 ${ }^{[2 ~ 3]}$, 一般发育于大洋岛弧, 形成时间较晚, 空间上远离海沟; 钾玄质岩石也大量形 成于大陆弧和后碰撞弧环境; 只有极少数钾玄质岩石产于板内环境 ${ }^{[4]}$, 因此, 钾玄质岩石在成 因岩石学和区域构造演化 (特别是古构造重建) 研究中都具有特殊的意义. 同时, 钾玄质岩石 与中温热液型金矿和斑岩型铜、金矿等金属矿床在时间和空间上密切共生 ${ }^{[4,5]}$, 对其研究不仅 具有潜在的经济地质意义, 而且在某种意义上, 钾玄质岩石已成为重要的找矿岩石学标志.

最近, 我们在桂东南地区进行中生代岩浆岩研究中, 陆续发现一些钾玄质侵入岩, 并在此 基础上初步厘定出一钾玄质侵入岩带. 本文将报道该钾玄质侵入岩带的基本特征和初步的岩 石地球化学研究结果. 